\title{
The detection of QTLs in barley associated with endosperm hardness, grain density, grain size and malting quality using rapid phenotyping tools
}

Cassandra K. Walker ${ }^{1,2}$, Rebecca Ford ${ }^{2}$, María Muñoz-Amatriaín ${ }^{3}$, Joe F. Panozzo ${ }^{1}$

${ }^{1}$ Department of Environment and Primary Industries, Horsham, VIC 3400, Australia

${ }^{2}$ Melbourne School of Land and Environment, The University of Melbourne, VIC 3010, Australia

${ }^{3}$ Department of Agronomy and Plant Genetics, University of Minnesota, St. Paul, MN 55108, USA

\begin{abstract}
Using a barley mapping population, 'Vlamingh' $\times$ 'Buloke' $(\mathrm{V} \times \mathrm{B})$, whole-grain analyses were undertaken for physical seed traits and malting quality. Grain density and size were predicted by digital image analysis (DIA), while malt extract and protein content were predicted using near infrared (NIR) analysis. Validation of DIA and NIR algorithms confirmed that data for QTL analysis was highly correlated $\left(\mathrm{R}^{2}>0.82\right)$, with high RPD values (the ratio of the standard error of prediction to the standard deviation, 2.31 to 9.06). Endosperm hardness was measured on this mapping population using the SKCS. Grain density and endosperm hardness, were significantly inter-correlated in all three environments $(r>0.22, \mathrm{P}<0.001)$, however other grain components were found to interact with the traits. QTL for these traits were also found on different genomic regions, for example, grain density QTLs were found on chromosomes $2 \mathrm{H}$ and $6 \mathrm{H}$, whereas endosperm hardness QTLs were found on $1 \mathrm{H}, 5 \mathrm{H}$, and 7H. In this study, the majority of the genomic regions associated with grain texture were also
\end{abstract}


co-incident with QTLs for grain size, yield, flowering date and/or plant development genes. This study highlights the complexity of genomic regions associated with the variation of endosperm hardness and grain density, and their relationships with grain size traits, agronomic-related traits, and plant development loci.

\section{Key words}

Non-destructive tools, Digital Image Analysis, grain density, endosperm hardness, grain size, QTL 


\section{Introduction}

Barley (Hordeum vulgare L.) is the fourth most important cereal crop in the world and its grain is mainly used for animal feed, malting and brewing. Grain texture is an important enduse quality parameter, associated with the malting and processing quality (Holopainen et al. 2005; Mayolle et al. 2012; Psota et al. 2007; Allison 1986; Walker and Panozzo 2011). Two components of grain texture are endosperm hardness and grain density.

Endosperm hardness is a physicochemical component of grain texture, barley with a harder endosperm requires more energy to grind (Camm et al. 1990; Psota et al. 2007), and is associated with higher vitreosity (Mayolle et al. 2012; Holopainen et al. 2005), slower water uptake (Mayolle et al. 2012; Gamlath et al. 2008), higher protein content (Camm et al. 1990; Walker and Panozzo 2011), and denser grain (Walker and Panozzo 2011). Barley with softer endosperm contains lower $\beta$-glucans (Gamlath et al. 2008; Psota et al. 2007), lower content of non-starch polysaccharides (Gamlath et al. 2008), modifies faster in the malting process with higher malt extract (Psota et al. 2007; Allison 1986), and has brighter grain (Nair et al. 2010). Grain density is a measure of the compactness of a seed. Grain with a lower density has a mealy endosperm that contains loosely packed starch granules in a discontinuous protein matrix interspersed with vacuous spaces (Nair et al. 2010; Psota et al. 2007; Nair et al. 2011; Briggs et al. 2001; Chang 1988; Fang and Campbell 2000). Physical traits, such as grain weight and size, are used routinely to classify the harvest quality of barley. Large and plump grains are thought relate to even water uptake and modification, and higher extractable sugar content ( $\mathrm{Li}$ et al. 2008; Agu et al. 2007). The relationship between endosperm hardness, grain density, grain size, malting and processing quality remains a focus of research. 
Plant developmental genes govern the genetic expression of grain size and weight traits (Coventry et al. 2003; Ayoub et al. 2002; Bingham et al. 2007). These grain traits are affected by grain yield, assimilate (source) availability, number of grains per $\mathrm{m}^{2}$ (sink), flowering date, carbohydrate accumulation and deposition, and the rate and duration of grain filling (Coventry et al. 2003; Hayes et al. 2003). The formation and structure of the starch and protein matrix in the endosperm during grain development also contributes to the variation in texture of barley grain (Brennan et al. 1996). The link between plant development, grain yield, grain size, malting quality and grain texture remains unclear. Therefore, to gain an understanding of the genomic control of grain texture, traits such as grain size, weight, volume, yield, and plant flowering date should also be considered.

Several phenotyping tools have been used to assess grain quality, structure and shape. Three of these tools, namely single kernel characterisation system (SKCS), digital image analysis (DIA), and near infrared (NIR) spectroscopy, can assess multiple traits simultaneously on a small grain sample. The SKCS is used to determine endosperm hardness and can measure the variation within cereal mapping populations (Wang et al. 2008; Walker et al. 2011; Beecher et al. 2002; Turuspekov et al. 2008; Morris et al. 1999). DIA is an emerging non-destructive tool used to measure the variation in appearance and grain shape by recording individual grain images (Walker and Panozzo 2012; Walker et al. 2009; Ayoub et al. 2002; Edney et al. 2005; Williams et al. 2012). NIR spectroscopy is a non-destructive, rapid tool used to assess a range of traits including grain protein content and hardness (Walker et al. 2011; Fox et al. 2007; Beecher et al. 2002). 
Endosperm hardness, as measured by the SKCS, is calculated by the force and time taken to crush a grain, the moisture content, and the grain weight (Walker et al. 2011; Pearson et al. 2007). QTLs associated with SKCS hardness have been identified at the $H a$ locus on chromosome arm 5HS, and on chromosomes 1H, 2H, 4H, 6H and 7H (Beecher et al. 2002; Walker et al. 2011; Swanston 1995; Fox et al. 2007).

Grain density, as opposed to the bulk density, is a grain texture trait of little research focus in barley due to difficulty in measuring rapidly. Currently displacement methods are used to measure the grain volume so that grain density can be calculated, however these methods are labour intensive and impractical when measuring hundreds of samples (Walker and Panozzo 2011). Alternatively, grain density on individual kernels has been estimated using grain volume measurements from 2-D digital images with moderate success $(\mathrm{r}=0.63, \mathrm{P}<0.01$ ) (Walker and Panozzo 2012). However, a higher accuracy in calculating grain density and grain volume, potentially achieved through 3-D imaging methods, is required for mapping and detection of QTL associated with grain density.

Two-dimensional DIA has also been used to derive grain size and shape data on individual barley grains (Walker and Panozzo 2012; Ayoub et al. 2002; Nielsen 2003). Data from 2-D images can be used to calculate grain length and major-width (Walker and Panozzo 2012; Sýkorová et al. 2009), however the third dimension (minor-width) was not measured. The minor-width is an important trait for the malting industry, impacting on how barley is graded. Industry reference methods, using nested slotted sieves, sort the grain into size groups and the minor-width determines whether the grain will fall through or remain on top of the sieves (Black et al. 2008). QTLs specifically associated with DIA of the grain minor-width, similar to grain density, are yet to be reported in barley. 
2-D DIA revealed QTL for grain size and shape on chromosomes $2 \mathrm{H}$ (near the Vrs-1 locus) (Komatsuda et al. 2007) and 4H (near int-c) (Ramsay et al. 2011) in a two-row/six-row mapping population (Ayoub et al. 2002). Both QTLs were previously associated with grain plumpness and weight (Marquez-Cedillo et al. 2001; Marquez-Cedillo et al. 2000). Subsequently, grain plumpness and weight QTLs were detected on all seven chromosomes (Mather et al. 1997; Walker et al. 2011; Moody et al. 2009; Coventry et al. 2003). These regions are thought to be associated with plant developmental genes, such as; the vernalisation loci (Karsai et al. 2008; Szücs et al. 2007), spike row number (Karsai et al. 2008), photoperiod response (Karsai et al. 2008), intermedium spike traits (Ramsay et al. 2011; Komatsuda and Mano 2002), and phytochromes involved with regulating flowering time (Szücs et al. 2006). DIA has the potential to reveal QTLs associated with multiple grain size traits, such as the dimensions of the grain, volume and density within mapping populations so as to build on and dissect current genomic knowledge.

The industry reference method for determining malt extract, a key malting quality trait, involves a 6-8 day controlled germination and kilning process, measuring the fermentable sugars in the malt (EBC-4.5.1 1998; IOB 1991). The majority of malt extract QTLs, identified on chromosome $1 \mathrm{H}$ and chromosome arms $2 \mathrm{HS}, 3 \mathrm{HL}, 4 \mathrm{HS}, 5 \mathrm{HL}$ and 7HL, have been based on industry reference methods (Mather et al. 1997; Panozzo et al. 2007; Thomas et al. 1996; Gao et al. 2004) NIR-based screening was introduced to assist in the rapid selection of malting quality traits, such as grain protein content and malt extract, in barley in early generations (Bezant et al. 1997; Black and Panozzo 2002). For this, pre-cursors in the spectra measured on unmalted barley were correlated to malt extract values. Bezant et al (1997) used NIR-predicted malt extract on ground barley and determined genomic regions associated with 
this trait. A major benefit of identifying malt extract-related QTLs using NIR predicted values would be a greater understanding of which genomic regions are associated with grain texture and malting quality. However, rigorous validation against standard methods would be required in order to ensure accuracy of the calibration (Panozzo et al. 2007).

The goals of this study were to: (1) develop non-destructive, accurate, rapid tools for measuring grain texture, grain size and malting quality-related traits; (2) identify QTLs for grain texture, malt-quality, grain size, grain yield and flowering date using a doubled-haploid population of 289 lines genotyped with 1,536 SNPs; (3) integrate published genes and QTL data related to plant development and malting quality along the doubled-haploid population map based on locations in the barley consensus map; and, (4) determine if the QTLs associated with the assessed traits were co-located and/or align with the published genes integrated along the map. The results of this study add to the existing knowledge and justification of potential regions for targeted selection of barley grain texture for breeding purposes.

\section{Materials and methods}

\section{Plant materials}

Two-hundred and eighty nine doubled-haploid (DH) lines developed from a cross between the barley varieties Vlamingh and Buloke were used in this study. Vlamingh and Buloke are tworow commercial malting varieties with similar malting quality characteristics and phenology, but that contrast in pedigree, grain hardness, grain density and grain plumpness. Buloke is more widely adapted in terms of disease resistance and yield potential, and Vlamingh has 
superior grain plumpness. The DH population was grown in non-replicated trials with grid controls in three environments over a one year period (2007); under rainfed conditions at Lake Bolac and Horsham, and under irrigated conditions at Horsham.

\section{SNP genotyping and linkage mapping}

Genomic DNA was extracted from barley plants according to the method described by Cane et al. (2004). The 1,536 SNPs of the Illumina barley oligo pool assay (BOPA1) (Close et al. 2009) were used to genotype the 'Vlamingh' $\times$ 'Buloke' $(\mathrm{V} \times \mathrm{B})$ population (Close et al. 2009; Hyten et al. 2008). SNP data curation and genetic map construction were as described by Muñoz-Amatriaín et al. (2011). Briefly, monomorphic and low-quality markers, as well as, problematic and potential duplicated individuals were removed from the dataset. The resultant 440 SNPs and $289 \mathrm{DH}$ lines were used for linkage map construction, using the software tool MSTmap (Wu et al. 2008), with a cut-off $p$-value of 0.000001, a maximum distance between markers of $15.0 \mathrm{cM}$, no estimation before clustering, the COUNT objective function, and the Kosambi distance function.

\section{Phenotypic measurements}

Grain yields (t/ha) from harvest were recorded at the three sites (Moody et al. 2009). Flowering dates (the Julian Day, JD, where $50 \%$ of heads were at Zadok growth stage 51) were also recorded on two sites of the three sites, Horsham (rainfed) and Horsham (irrigated) (Moody et al. 2009).

Endosperm hardness, grain density, malt extract, grain protein content (GPC), grain weight, grain volume, grain length, major-width and minor-width were measured on a $200 \mathrm{~g}$ grain subsample of each plot using the SKCS, image analysis and NIR techniques. 
Endosperm hardness was measured by an SKCS 4100, Perten Instruments, Springfield, USA (Walker et al. 2011).

Malting quality traits, GPC and malt extract, were predicted on whole grain barley using a NIRSystems XDS (Foss Pacific Pty Ltd, Denmark), as described by Black and Panozzo (2002), Panozzo et al. (2007) and Walker et al. (2011), both traits were expressed as a percent dry basis.

The grain weight (mg) was measured as the mass of 500 individual grains divided by 500 .

The whole grain samples were analysed through a 3-D digital image analyser (Foss Pacific Pty Ltd, Denmark). Matlab (version 7.7.0.471, R2011b), with the image processing and statistical toolbox was used to process the Portable Network Graphics (PNG) images and determine grain size and volume. Any images containing foreign material, cracked and split grains were filtered from the analyses as described by Walker et al. (2009) and Walker and Panozzo (2012). Grain length and major-width (widest width section of the grain) were estimated from pixel lengths of the collected 2-D PNG images (Walker and Panozzo 2012). The minor-width (thinnest width section of the grain and the third dimension) was obtained from the laser cross-section of the same grain. The volume was calculated using the summation cylindrical segments along the length of the 2-D grain image and the corresponding 3-D using laser cross-section of the grain, proposed by Walker and Panozzo (2012). This geometric approach was modified by using the minor-width measurements of the laser cross-section of the grain instead of the assumptions made from the correlation between the major and minor-width. 
The grain density $\left(\mathrm{mg} / \mathrm{mm}^{3}\right)$ of a sample was calculated by dividing the grain weight $(\mathrm{mg})$ by the grain volume $\left(\mathrm{mm}^{3}\right)$ as measured by DIA.

\section{Validation of Quality Traits}

Three subsets of samples from each of the three trial environments were used for validation purposes. One subset, consisting of twenty five samples, was assessed using callipers for grain length, grain major-width and grain minor-width (Walker and Panozzo 2012); a second subset, consisting of thirty eight samples, was measured for grain volume, and grain density using gas displacement (Walker and Panozzo 2011); GPC was measured on a second subset, consisting of forty two samples, using the Dumas combustion nitrogen procedure (Panozzo et al. 2007); and the third subset, consisting of thirty eight samples, was malted and the malt extract measured using a modified EBC method (Panozzo et al. 2007).

Three statistical methods were used to evaluate the accuracy of predicting traits using NIR or DIA; the coefficient of determination $\left(\mathrm{R}^{2}\right)$, the standard error of prediction (SEP), and the $\mathrm{RPD}$, the ratio of the standard error of prediction (SEP) to the standard deviation (SD) of the reference data (Williams and Norris 2001; Black and Panozzo 2004; Natsuga and Kawamura 2006). The RPD is a descriptive statistic used to assess the predictive accuracy of a technique, such as NIR, where the higher the value, the lower the signal to noise ratio in the data set compared to reference methods. Ranges of RPD values have been used to evaluate NIR for various applications, from moderate accuracy for early generation breeding screening to highly accurate for industrial process and quality control (Williams and Norris 2001). Four RPD ranges defined by Natsuga and Kawamura (2006) were adopted by this study. A reported RPD value of less than 2.30 indicated poor accuracy in the validation set, and is not 
recommended for use in genomic studies; 2.31-3.00, indicated that the algorithm may be adequate to classify the trait into high and low categories, however each QTLs' significance and location should be further validated; 3.01-5.00 indicated the algorithm provided sufficiently accurate data for reliable QTL analysis; > 5.01 indicated the algorithm was highly correlated with low error compared to the reference method, and was highly applicable for predicting traits for genomic studies.

\section{QTL analysis}

Spatial models were fitted for each trait/environment combination using GenStat (V 15.1.0.7720), where non-genetic components, such as spatial variation, were estimated. GenStat was used to calculate; the heritability $\left(\mathrm{h}^{2}\right)$ and predicted means, BLUEs (Best Linear Unbiased Estimates), of each quality trait, and the correlation coefficients between environments. QTLs for the predicted means of grain yield, flowering date, grain texture, grain size and malting quality traits were resolved by performing Composite Interval Mapping (CIM). Windows QTL Cartographer (V 2.5_011) model 6 was used and optimised with 5-10 markers to control for the genetic background on a 10cM window size (Hervé et al. 2001). The LOD scores for QTL detection were calculated based on 1000 permutations at $\mathrm{p} \leq 0.05$ for CIM, with a walk speed of $2 \mathrm{cM}$, a threshold was considered significant when the LOD score was greater than 2.5 to minimise the risk of a Type II error (ie. not detecting a true QTL). The percent of the phenotypic variation explained by each QTL was estimated as the coefficient of determination $\left(\mathrm{R}^{2}\right)$. Consensus QTLs for a trait were considered to be significant and consistent if they were supported by at least two environments.

Previously published gene and QTL data related to plant development and malting quality were integrated into the $\mathrm{V} \times \mathrm{B}$ map based on their presence in the BOPA1 platform or their 
position was inferred based on the barley consensus map (Muñoz-Amatriaín et al. 2011) and OWB integrated map (Szücs et al. 2009).

The $\mathrm{V} \times \mathrm{B}$ genetic linkage map, and the indentified and aligned QTLs were drawn using MapChart (Voorrips 2002).

\section{Results}

Validation of the Non-destructive Phenotypic Analyses

Phenotypic measurements obtained using NIR and DIA and were compared to those obtained using reference methods. Significant correlations were found for all malt-quality and grain size trait values, with the coefficients of determination $\left(\mathrm{R}^{2}\right)$ ranging from 0.82 (grain density) to 0.99 (grain major-width and GPC), with low SEPs (Fig. 1).

The RPD values for estimating grain length, volume and GPC were greater than 5.01 (Fig. 1: a, c, and f), and indicated that the algorithms were highly applicable for predicting traits for QTL analyses. The RPD values for major-width, minor-width, and malt extract were greater than 3.41 (Fig. 1a, b, c, d, f and g), and indicated that the algorithms were sufficiently accurate to use for genomic analyses. The grain density predictions, calculated using 3-D DIA grain volume and grain weight, were adequate for use in genomic studies with an acceptable error $(\mathrm{RPD}=2.31, \mathrm{SEP}=0.011)$, when compared to gas displacement measurements (Fig. 1e).

\section{Phenotypic characterisation}


The parents of the DH population, Vlamingh and Buloke, were significantly different for endosperm hardness, grain density, malt extract, grain weight, volume, length and minorwidth in all three environments, and for grain major-width in two environments (Table 1). Vlamingh and Buloke were not significantly different from each other for grain yield and flowering date (Table 1). Vlamingh had a softer and less dense endosperm with shorter, wider and, therefore, more spherical grain. Buloke had a higher malt extract content, grain weight, length and volume.

The DH lines (DHLs) grown in all three environments were more diverse in endosperm hardness, grain density, malt extract, GPC, grain weight, volume, length, minor, major-width, yield, and flowering date than the parents, indicating transgressive segregation (Table 1). All traits were normally distributed within the DHLs at each environment (Supplemental Fig. 1).

Samples grown at Lake Bolac (rainfed) and Horsham (irrigated) had higher grain weight, larger grain volume, wider grain and softer endosperms than those grown at Horsham (rainfed) (Table 1). All three environments had similar distribution ranges of malt extract and GPC.

All phenotypes, with the exception of GPC, were significantly correlated $(\mathrm{P}<0.001)$ between the environments (Table 2$)$. Significant negative correlations $(\mathrm{P}<0.001)$ were observed across all three environments for: grain density and minor-width; grain density and weight; density and major-width; density and volume; endosperm hardness and major-width; and, malt extract and GPC. Significant positive correlations $(\mathrm{P}<0.001)$ were observed across all environments between the grain size traits: grain weight and grain volume; grain major and minor-width; major-width and volume; major-width and weight; length and volume; length and weight; 
and, volume and minor-width. Significant correlations $(\mathrm{P}<0.01)$ were found among all three environments between: grain minor-width and volume; minor-width and weight; and, endosperm hardness and minor-width. Correlations were reported at two of the three environments between endosperm hardness and grain density, and, also, for endosperm hardness and malt extract.

\section{QTL mapping}

In total, 232 significant QTLs were detected for the eleven grain traits across the three environments assessed (supplemental Table 1). Consensus QTLs (i.e. QTLs identified at more than two environments) for grain texture, grain size, malting extract, grain protein content, grain yield and flowering date traits were identified on all seven chromosomes (Table 3).

Genes reported to influence plant development and malting quality that may influence grain texture, size, shape, yield and flowering date found were identified (Table 4). The genomic locations for these candidate genes were identified within the 'Vlamingh' $\times$ 'Buloke' $(\mathrm{V} \times \mathrm{B})$ map using SNP markers to align their locations from barley consensus maps and other barley gene studies (Fig. 2).

\section{Chromosome $1 \mathrm{H}$}

QTLs associated with endosperm hardness were identified on chromosome $1 \mathrm{H}$, which accounted for $10.8-21.7 \%$ of the phenotypic variance (Fig. 2 and Table 3). The nearest marker to the QTL peaks was 2_1000 in all three environments, with the donor alleles contributed from the harder endosperm parent, Buloke; decreasing SKCS hardness by 2.082.72 units (Table 3, supplemental Table 1). QTLs were also detected for malt extract, flowering date and grain yield in this genomic region, but were only reported at one 
environment (irrigated Horsham, supplemental Table 1). The Aglu3 and $H v B D G$ genes (Table 4) were coincident with this genomic region (Table 4, Fig. 2). The consensus QTLs for endosperm hardness on $1 \mathrm{H}$ had the highest LOD scores compared with other genomic associations with endosperm hardness within the $\mathrm{V} \times \mathrm{B} \mathrm{DH}$ mapping population.

In close proximity to this genomic region were consensus QTLs associated with grain volume and length (Fig. 2). Buloke with longer and larger grain than Vlamingh, contributed the alleles which decreased grain size at these loci. These QTLs were coincident with the Vrs3 and int- $a$ loci, which are reported to control vernalisation and alter the size of lateral spikelets (Table 4, Fig. 2).

\section{Chromosome $2 \mathrm{H}$}

Consensus QTLs for grain density were located near the centromere of chromosome $2 \mathrm{H}$, where Buloke contributed the alleles at these loci for decreasing grain density. There were two significant genomic regions between markers 1_1072 to 1_0651 and 2_1258 to 2_0960, explaining 4.0-8.8\% of the phenotypic variation (Table 3). Consensus QTLs were detected for grain volume, grain length, grain weight, and flowering date and were coincident with the grain density QTLs. Alleles from Vlamingh increased grain volume, grain weight and grain length, whereas alleles from Buloke decreased flowering date (Table 3, Fig. 2). The grain size QTLs accounted for a large portion of the phenotypic variation; for grain volume 16.6$19.5 \%$, for grain weight $6.6-12.5 \%$, and for grain length $17.1-24.7 \%$ (Table 3). The consensus QTLs associated with flowering date accounted 7.2-8.7\% of the phenotypic variation. This genomic region was also in close proximity $(\sim 7 \mathrm{cM})$ with the barley cellulose synthase-like (HvCsIF) genes (Table 4, Fig. 2). 
Consensus QTLs for malt extract were reported on the arm 2HL at two environments, where Buloke contributed the alleles decreasing extract content, and was located between markers 2_1459 to 2_0715. In close proximity $(\sim 15 \mathrm{cM})$ was the Aglu5 gene.

\section{Chromosome $3 H$}

On the long arm of chromosome $3 \mathrm{H}$, consensus QTLs were detected for grain length, and grain volume. Two QTLs were found for grain length (marker intervals 2_0662 to 2_0612; and 2_1272 to 2_0339). One QTL was identified for grain volume (marker interval 2_0612 to 2_1272). Buloke contributed the alleles for the three consensus QTLs reported, decreasing the grain length and volume. One locus associated with grain length (marker interval, 2_0662 to 2_0612) was also coincident with QTLs found in one environment for endosperm hardness, malt extract, grain yield and flowering date (Supplementary Table 1).

\section{Chromosome $4 H$}

On the long arm of chromosome 4H, consensus QTLs were found for endosperm hardness, with the nearest marker being 2_0044 (Fig. 2, supplementa1 Table 1). These QTLs explained between $3.2-4.8 \%$ of the phenotypic variance, and the Vlamingh alleles contributed to an increase in hardness of 1.00-1.33 SKCS units (Table 3). This genomic region was coincident with consensus QTLs associated with flowering date, and the vernalisation gene, $V R N-H 2$, and the Bmyl gene (Table 4, Fig. 2). QTLs associated with grain major-width and grain yield, in one environment, were also coincident with this region (supplemental Table 1).

Three genomic regions were reported to have consensus QTLs for malt extract on chromosome $4 \mathrm{H}$ at all three environments. Vlamingh, lower in malt extract, contributed the alleles that increased extract for all QTLs observed on this chromosome (Table 3). The first 
genomic region for malt extract, with the marker interval 2_1122 to 1_0411, explained between 7.9-13.0\% of the phenotypic variation. Consistent QTLs, reported for grain weight and grain minor-width, were detected in this first genomic region associated with malt extract (Fig. 2). The Buloke allele decreased the grain minor-width and weight among these QTLs associated with grain size. This first genomic region, associated with malt extract and grain size, was coincident with the $P h y A$ and $P h y B$ genes, which are involved with the regulation of flowering, and the QTL2 gene associated with malting quality (Table 4, Fig. 2). The second genomic region on chromosome $4 \mathrm{H}$, near the centromere between markers 1_1244 and 2_0361, reported at two environments, was associated with malt extract (Fig. 2). This was coincident with the DTDP gene (Table 4, Fig. 2). The third genomic region on the long arm of chromosome 4H, significant for malt extract, was coincident with significant QTLs for GPC (Fig. 2).

On the short arm of chromosome $4 \mathrm{H}$, there were two genomic regions associated with grain volume, and grain major-width. Vlamingh contributed the alleles in both regions, increasing grain size.

\section{Chromosome $5 H$}

On chromosome $5 \mathrm{H}$, there were many consensus QTLs associated with endosperm hardness, grain major-width, minor-width, weight, length, and volume.

QTLs for endosperm hardness were detected near the centromere of chromosome $5 \mathrm{H}$ at all three environments, these consensus QTLs explained 4.3-12.5\% of the phenotypic variation. These QTLs showed an increase in endosperm hardness contributed from the Vlamingh alleles (Table 3). In this region, coincident QTLs were significantly associated with grain 
minor-width, major-width, length and grain yield (Fig. 2). Grain length explained between 22.4-22.6\% of the phenotypic variation, major-width explained between 5.4-6.3\%, and minorwidth between 5.7-12.9\%. The alleles for increased grain length were from Vlamingh, the shorter grained parent; and, the alleles which decreased grain minor and major-width were from Buloke, the parent with the thinner grain. The location of the $\mathrm{Ha}$ locus, according to the barley consensus map, when aligned to the $\mathrm{V} \times \mathrm{B}$ map, was not coincident $(\sim 38.5 \mathrm{cM}$ apart) consensus QTL associated with endosperm hardness on the short arm of 5H near the centromere (Fig. 2).

Consensus QTLs detected on chromosome 5H, between markers 1_0641 and 2_0367, were associated with grain length and grain weight. These explained between 7.2-13.8\% (grain length) and 5.8-9.1\% (grain weight) of the phenotypic variation, the alleles were contributed from Vlamingh and increased grain length and weight.

The most significant consensus QTLs associated with grain minor-width and major-width, were reported on the long arm of chromosome $5 \mathrm{H}$, located in the marker interval between 1_1071 and 1_1490. The QTLs accounted for 7.8-13.1\% of the phenotypic variation for grain minor-width, and 9.9-15.5\% for the major-width. A consensus QTL associated with grain volume was also reported in this region, and in close proximity $(\sim 20 \mathrm{cM})$ to this region were QTLs associated with grain length. Alleles from Vlamingh increased grain minor-width, major-width, and volume, and alleles from Buloke decreased grain length (Table 3).

Within the marker interval 1_1456 to 1_1071, were consensus QTLs that also had a positive effect on grain minor and major-width, and grain weight. These QTLs explained between 6.8-14.6\% for major-width, 3.2-10.6\% for minor-width and 3.6-8.3\% for grain weight. 
Vlamingh contributed all the alleles for these traits. The QTLs were coincident with a flowering date QTL (supplementary Table 1), and the vernalisation gene (VRN-H1) and the PhyC gene, involved with the regulation of flowering (Table 4, Fig. 2).

Two genomic regions for grain major-width, grain volume and grain weight were detected within the marker interval 2_1480 to $1 \_4077$. The contributing alleles were from Buloke in all traits, which decreased grain major-width, volume and weight. This region was coincident with the $F r 2$ and $C B F_{-}$cluster genes, which control frost resistance and Dehydration Responsive Elements (DRE)-binding factors (Table 4).

\section{Chromosome $6 H$}

A consensus genomic region that had significant QTLs for grain density was on the long arm on chromosome $6 \mathrm{H}$. These QTLs explained 3.9-8.2\% of the phenotypic variation, where the Buloke alleles decreased grain density. The grain density QTLs on chromosome $6 \mathrm{H}$ were coincident with consensus QTLs detected for grain weight, length, and volume, where Vlamingh contributed the alleles increasing these grain weight and size traits (Table 3 ).

\section{Chromosome $7 \mathrm{H}$}

Consensus QTLs associated with endosperm hardness were detected on the short arm of chromosome $7 \mathrm{H}$ for two environments, this explained $5.3-6.8 \%$ of the phenotypic variance (Table 3). The alleles were contributed from the softer parent, Vlamingh, increasing endosperm hardness indicating transgressive segregation, and were located in the marker interval 2_0993 to 1_0056. These consensus hardness QTLs were coincident with consensus QTLs for grain yield and flowering date (Table 4, Fig. 2). The VRN-H3 gene was also coincident with this genomic region (Table 4, Fig. 2). Significant QTLs detected for grain 
length, major-width, minor-width and protein content from one environment, were also coincident with this region associated with endosperm hardness (supplemental Table 1).

On the long arm of chromosome $7 \mathrm{H}$ there were consensus QTLs detected for grain length (Fig. 2). These explained between $2.0-4.4 \%$ of the phenotypic variation, where Vlamingh contributed the alleles which increased grain length. The QTLs were detected between the marker interval 2_0808 to 1_1243.

\section{Discussion}

The development of accurate high-throughput and non-destructive phenotyping tools, such as DIA (Williams et al. 2012) and NIR (Black and Panozzo 2002), will enhance the knowledge gained from genomics studies (Xu and Crouch 2008). Validating secondary techniques is essential in genomic studies to ensure significant and accurate regions are detected with confidence. In this study, validation statistics indicated that data from DIA and NIR were significantly correlated $\left(\mathrm{R}^{2}>0.82\right)$, with acceptable standard errors, compared to reference data (Fig. 1). For grain length, volume, and protein content, the algorithms were the most accurate, and highly applicable for use in genomic studies. Algorithms calculating grain major-width, minor-width, and malt extract were accurate for resolving significant QTLs (Table 3, Fig. 2). The algorithm used to calculate grain density was adequate for reporting significant genomic regions (Table 3, Fig. 2), as these regions were also coincident with grain weight and volume QTLs, located on chromosomes $2 \mathrm{H}$ and $6 \mathrm{H}$. 
The grain texture traits; endosperm hardness and grain density, were significantly intercorrelated in all three environments (Table 2). In a previous investigation, different grain components were found to interact independently of these traits, even though they were significantly correlated (Walker and Panozzo 2011). In this study grain volume and weight were significantly correlated to grain density, but not endosperm hardness, and grain length was significantly correlated with endosperm hardness, but not grain density (Table 2). No coincident consensus QTLs were detected that control both grain density and endosperm hardness. For endosperm hardness, consensus QTLs were detected on chromosomes $1 \mathrm{H}, 4 \mathrm{H}$, $5 \mathrm{H}$ and $7 \mathrm{H}$, whereas, for grain density, consensus QTLs were detected on chromosomes $2 \mathrm{H}$ and $6 \mathrm{H}$. Therefore, even though endosperm hardness and grain density are interdependent traits (Walker and Panozzo 2011), different genomic regions can be manipulated independently to influence endosperm hardness or grain density.

There is a apparent association between the grain density and barley processing quality (Fang and Campbell 2000; Walker and Panozzo 2011). This association is supported by significant correlations between grain density and grain size traits (Table 2). Also, different grain components and genomic regions were found to be associated with grain density, compared with those associated with endosperm hardness. Therefore, understanding the genomic regions associated with grain density would add to our knowledge in understanding the impact of grain texture on processing quality. Grain density is calculated by dividing the weight by the volume. QTLs for grain weight and volume generally had higher LOD scores and smaller intervals, than those detected for grain density. Also, we detected a genomic region on the long arm of chromosome 5H, between markers 1_1290 and 1_0477, significantly associated with grain weight and volume but not grain density. This region, on $5 \mathrm{H}$, is likely to be associated with grain density, but the estimate of grain density was not 
sensitive enough to detect significant QTL in this region Coincident QTLs identified for both grain weight and volume may be sufficient to identify genomic regions associated with grain density, although this needs validation with other populations and environments.

The largest and most significant consensus QTLs associated with endosperm hardness for the $\mathrm{V} \times \mathrm{B}$ mapping population were found on chromosome $1 \mathrm{H}$, where the alleles from Buloke decreased hardness. QTLs for endosperm hardness in the same region were also reported by Beecher et al. (2002) in the 'Steptoe' $\times$ 'Morex', Fox et al. (2007) in the 'Patty' $\times$ 'Tallon', and Walker et al. (2011) in the 'Arapiles' $\times$ 'Franklin' barley mapping populations. The traits, endosperm hardness and malt extract were significantly correlated within all three environments, confirming a relationship between endosperm hardness and malt extract (Table 2). In this study, there was a significant QTL for malt extract in the same region of $1 \mathrm{H}$, where favourable alleles increased extract (from Vlamingh). Malting quality QTLs were reported to be coincident with endosperm hardness QTLs in the 'Arapiles' $\times$ 'Franklin' (Walker et al. 2011; Panozzo et al. 2007) and 'Steptoe' × 'Morex' (Beecher et al. 2002) barley populations. Panozzo et al (2007) suggested that there is benefit in using marker assisted selection (MAS) to manipulate malting quality in this genomic region on chromosome $1 \mathrm{H}$. However, this region was also coincident with a flowering date QTLs for this DH population. So although this region is linked with endosperm hardness and malt extract, it may be an inappropriate region for MAS as the genes influencing grain quality may also be tightly linked to flowering date.

Consensus QTLs associated with endosperm hardness, grain weight, minor-width, majorwidth, and grain yield were coincident on the short arm of chromosome 5H. Grain weight has been shown to influence endosperm hardness in other studies (Turuspekov et al. 2008; Galassi 
et al. 2011; Chen et al. 2009). In addition, the short-arm of chromosome 5H has been associated with Hin genes (Beecher et al. 2002; Chen et al. 2009; Galassi et al. 2011; Takahashi et al. 2010), which is considered by some researchers to control endosperm hardness (Beecher et al. 2002; Turuspekov et al. 2008). The location of the $H a$ locus in this study was not closely linked with the endosperm hardness QTLs ( 38.5 cM apart, Fig. 2). Therefore, this study highlights the complexity of the relationships between endosperm hardness, grain yield, and grain size traits, and if endosperm hardness is in fact strongly linked to the functionality of the Hin genes.

Malt extract is a complex trait, where many genomic regions along the chromosome have been shown to influence various components associated with this trait. Consensus QTLs for malt extract content were not found to be coincident with consensus QTLs for endosperm hardness or grain density. In a recent study of structural components of the grain, endosperm hardness and grain density were found to influence water diffusivity but not influence the hydrolytic activities of enzymes involved in improving malt extract (Mayolle et al. 2012). In this study, QTLs for malt extract were coincident with regions associated with hydrolytic enzymes, namely chromosome 4HL (also coincident with GPC), 2H, and 1H (Panozzo et al. 2007; Szücs et al. 2009; Collins et al. 2003). Also, malt extract QTLs on chromosome 4HS, near the centromere, were found to be coincident with QTLs associated with grain weight, minor-width and flowering date. Therefore, genomic regions associated with malt extract that are coincident with hydrolytic enzymes or grain size traits, need to be further examined so that we can gain an understanding into the genetic basis of malting quality and how each region affects extract. 
Studies in wheat using DIA have indicated that grain length and major-width are often not genetically associated (Campbell et al. 1999). Williams et al. (2012) detected independent QTLs for grain length, major-width and minor-width. In this study, QTLs were observed for different grain size components in different genomic regions using DIA. QTLs associated with grain length were detected on 7H, QTLs associated with grain length and volume were detected on chromosome 1H, QTLs associated with grain length, volume and weight were detected on chromosome $2 \mathrm{H}$ and $6 \mathrm{H}$. Whereas, QTLs associated with grain volume, majorwidth, minor-width and weight were detected on chromosome $4 \mathrm{H}$, and QTLs associated with grain minor-width, major-width, weight and length were detected on 5H. However, many of these regions were associated with grain yield, flowering date and genes reported to influence plant development (Fig. 2). Often genomic regions associated with improved grain plumpness are also associated with grain yield, flowering date and/or malt-quality related traits. If genomic regions could be identified for grain length, major-width, minor-width or weight traits and were proven to be unrelated to yield components then such traits may improve grain plumpness without having deleterious effect on yield or malt-quality related traits.

Consensus mapping studies increase our understanding of the complexity and association between grain quality traits and agronomic traits in barley. In the $\mathrm{V} \times \mathrm{B}$ mapping population all genomic regions significantly associated with the grain texture traits, endosperm hardness and grain density, were coincident with QTLs for grain size, grain yield, and/or flowering date, with the exception of the one region detected on chromosome $6 \mathrm{H}$ (Fig. 2). Vernalisation genes, photoperiod genes, and barley cellulose synthase-like genes were coincident with grain density QTLs on chromosome $2 \mathrm{H}$, and endosperm hardness QTLs on chromosomes $4 \mathrm{H}, 5 \mathrm{H}$, and $7 \mathrm{H}$. As genes and their functionalities are identified along the barley genome, so to will 
our understanding of how agronomic traits, such as grain yield, flowering date, and plant development genes, interact with grain texture, size and malt quality-related QTLs.

\section{Acknowledgments}

David Moody, InterGrain, for developing the 'Vlamingh' $\times$ 'Buloke' population, and providing advice throughout the research. The Grains and Forage Chemistry Laboratory, Department of Primary Industries - Horsham, for their assistance in processing grain samples. Grains Research and Development Corporation and Department of Primary Industries in funding the research.

\section{References}

Agu RC, Brosnan JM, Bringhurst TA, Palmer GH, Jack FR (2007) Influence of corn size distribution on the diastatic power of malted barley and its impact on other malt quality parameters. Journal of Agricultural and Food Chemistry 55 (9):3702-3707

Allison MJ (1986) Relationships between milling energy and hot water extract values of malts from some modern barleys and their parental cultivars. J Inst Brew 92:604-607

Ayoub M, Symons SJ, Edney MJ, Mather DE (2002) QTLs affecting kernel size and shape in a two-rowed by six-rowed barley cross. TAG 105 (2/3):237-247. doi:10.1007/s00122002-0941-1

Beecher B, Bowman J, Martin JM, Bettge AD, Morris CF, Blake TK, Giroux MJ (2002) Hordoindolines are associated with a major endosperm-texture QTL in barley (Hordeum vulgare). Genome 45 (3):584-591

Bezant JH, Laurie DA, Pratchett N, Chojecki J, Kearsey MJ (1997) Mapping of QTL controlling NIR predicted hot water extract and grain nitrogen content in a spring barley cross using marker-regression. Plant Breeding 116 (2):141-145

Bingham IJ, Blake J, Foulkes MJ, Spink J (2007) Is barley yield in the UK sink limited? II. Factors affecting potential grain size. Field Crops Research 101 (2):212-220 
Black CK, Panozzo JF (2002) Predicting malting quality in whole grain malt compared to whole grain barley by near infrared spectroscopy. Paper presented at the Near Infrared Spectroscopy: Proceedings of the 10th International Conference, Korea,

Black CK, Panozzo JF (2004) Accurate Technique for Measuring Color Values of Grain and Grain Products Using a Visible-NIR Instrument. Cereal Chemistry 81 (4):469-474. doi:10.1094/cchem.2004.81.4.469

Black CK, Panozzo JF, Ford R (2008) Quantitative mapping of the chromosomal loci associated with physical grain traits in barley. Paper presented at the Proceedings of the 58th Australian Cereal Chemistry Conference, Surfers Paradise, Queensland,

Brennan CS, Harris N, Smith D, Shewry PR (1996) Structural differences in the mature endosperms of good and poor malting barley cultivars. Journal of Cereal Science 24 (2):171-177

Briggs DE, Sole SM, Bury P (2001) Flotation, a bulk-selection method for breeders which permits the selection of faster modifying barley grains. J Inst Brew 107 (3):151-156

Burton RA, Wilson SM, Hrmova M, Harvey AJ, Shirley NJ, Medhurst A, Stone BA, Newbigin EJ, Bacic A, Fincher GB (2006) Cellulose synthase-like CslF genes mediate the snthesis of cell wall (1,3;1,4)- $\beta{ }_{-\mathrm{D}}$-glucans. Science 311 (5769):1940-1942. doi:10.1126/science. 1122975

Caldwell KS, Langridge P, Powell W (2004) Comparative sequence analysis of the region harboring the hardness locus in barley and its colinear region in rice. Plant Physiology $136(2): 3177-3190$

Camm JP, Ellis RP, Morrison WR (1990) Milling energy: an investigation into the biochemical basis of hardness in cereals. Aspects in Applied Biology 25:121-130

Campbell KG, Bergman CJ, Gualberto DG, Anderson JA, Giroux MJ, Hareland G, Fulcher RG, Sorrells ME, Finney PL (1999) Quantitative trait loci associated with kernel traits in a soft $\times$ hard wheat cross. Crop Science 39 (4):1184

Cane K, Spackman M, Eagles HA (2004) Puroindoline genes and their effects on grain quality traits in southern Australian wheat cultivars. AJAR 55 (1):89-95. doi:10.1071/AR03108

Chang CS (1988) Measuring density and porosity of grain kernels using a gas pycnometer. Cereal Chemistry 65 (1):13-15

Chen G-y, Yang S-d, Li W-t, Li W, Wei Y-m, Zheng Y-l (2009) Variations of Single Nucleotide Polymorphism (SNP) of hordoindoline a gene (hina) and its relationships with kernel hardness in 92 North American barley varieties (Hordeum vulgare L.). Agricultural Sciences in China 8 (12):1440-1447. doi:10.1016/S1671-2927(08)603570

Chutimanitsakun Y, Nipper R, Cuesta-Marcos A, Cistue L, Corey A, Filichkina T, Johnson E, Hayes P (2011) Construction and application for QTL analysis of a Restriction Site 
Associated DNA (RAD) linkage map in barley. BMC Genomics 12 (1):4. doi:10.1186/1471-2164-12-4

Close T, Bhat P, Lonardi S, Wu Y, Rostoks N, Ramsay L, Druka A, Stein N, Svensson J, Wanamaker S, Bozdag S, Roose M, Moscou M, Chao S, Varshney R, Szücs P, Sato K, Hayes P, Matthews D, Kleinhofs A, Muehlbauer G, DeYoung J, Marshall D, Madishetty K, Fenton R, Condamine P, Graner A, Waugh R (2009) Development and implementation of high-throughput SNP genotyping in barley. BMC Genomics 10 (1):582. doi:10.1186/1471-2164-10-582

Collins HM, Panozzo JF, Logue SJ, Jefferies SP, Barr AR (2003) Mapping and validation of chromosome regions associated with high malt extract in barley (Hordeum vulgare L.). AJAR 54 (12):1223-1240. doi:10.1071/AR02201

Coventry SJ, Barr AR, Eglinton JK, McDonald GK (2003) The determinants and genome locations influencing grain weight and size in barley (Hordeum vulgare L.). AJAR 54 (12):1103-1115. doi:10.1071/AR02194

Cuesta-Marcos A, Szucs P, Close T, Filichkin T, Muehlbauer G, Smith K, Hayes P (2010) Genome-wide SNPs and re-sequencing of growth habit and inflorescence genes in barley: implications for association mapping in germplasm arrays varying in size and structure. BMC Genomics 11 (1):707. doi:10.1186/1471-2164-11-707

EBC-4.5.1 (1998) Extract of malt: congress mash European Brewery Convention AnalyticaEBC. Verlag Hans Carl Geranke-Fachverlag, Nurnberg, Germany.

Edney MJ, Izydorczyk MS, Symons SJ, Woodbeck N (2005) Measuring barley kernel colour and size to predict end use malt quality. Grain Research Laboratory/Industry Services collaborative study on valuing barley, 2005. Canadian Grains Commission, Winnepeg

Fang C, Campbell GM (2000) Effect of measurement method and moisture content on wheat kernel density measurement. Food and Bioproducts Processing 78 (4):179-186. doi:10.1205/09603080051065278

Fox GP, Osborne B, Bowman J, Kelly A, Cakir M, Poulsen D, Inkerman A, Henry R (2007) Measurement of genetic and environmental variation in barley (Hordeum vulgare) grain hardness. Journal of Cereal Science 46 (1):82-92. doi:10.1016/j.jcs.2006.12.003

Galassi E, Gazzelloni G, Taddei F, Muccilli V, Gazza L, Pogna N (2011) Kernel texture and hordoindoline patterns in barley (Hordeum vulgare). Molecular Breeding:1-12. doi:10.1007/s11032-012-9738-3

Galiba G, Vágújfalvi A, Li C, Soltész A, Dubcovsky J (2009) Regulatory genes involved in the determination of frost tolerance in temperate cereals. Plant Science 176 (1):12-19. doi:10.1016/j.plantsci.2008.09.016

Gamlath J, Aldred GP, Panozzo JF (2008) Barley (1-3; 1-4)-b-glucan and arabinoxylan content are related to kernel hardness and water uptake. Journal of Cereal Science 47:365-371. doi:10.1016/j.jcs.2007.05.017 
Gao W, Clancy JA, Han F, Jones BL, Budde A, Wesenberg DM, Kleinhofs A, Ullrich SE (2004) Fine mapping of a malting-quality QTL complex near the chromosome 4H S telomere in barley. TAG 109 (4):750-760. doi:10.1007/s00122-004-1688-7

Hayes PM, Castro A, Marquez-Cedillo L, Corey A, Henson C, Jones BL, Kling J, Mather D, Matus I, Rossi C, Sato K (2003) Genetic diversity for quantitatively inherited agronomic and malting quality traits. In: Von Bothmer R, van Hintum T, Knüpffer H, Sato K (eds) Diversity in barley. Elsevier Science Publishers, Amsterdam, The Netherlands,

Hervé D, Fabre F, Berrios EF, Leroux N, Chaarani GA, Planchon C, Sarrafi A, Gentzbittel L (2001) QTL analysis of photosynthesis and water status traits in sunflower (Helianthus annuus L.) under greenhouse conditions. Journal of Experimental Botany 52 (362):1857-1864. doi:10.1093/jexbot/52.362.1857

Holopainen URM, Wilhelmson A, Salmenkallio-Marttila M, Peltonen-Sainio P, Rajala A, Reinikainen P, Kotaviita E, Simolin H, Home S (2005) Endosperm structure affects the malting auality of barley (Hordeum vulgare L.). Journal of Agricultural and Food Chemistry 53 (18):7279-7287. doi:10.1021/jf050349b

Hyten D, Song Q, Choi I-Y, Yoon M-S, Specht J, Matukumalli L, Nelson R, Shoemaker R, Young N, Cregan P (2008) High-throughput genotyping with the GoldenGate assay in the complex genome of soybean. TAG 116 (7):945-952. doi:10.1007/s00122-0080726-2

IOB (1991) Recommended Methods of Analysis, 2. Ale, Larger and Distilling Malts. IOB, London

Karsai I, Szűcs P, Kőszegi B, Hayes PM, Casas A, Bedő Z, Veisz O (2008) Effects of photo and thermo cycles on flowering time in barley: a genetical phenomics approach. Journal of Experimental Botany 59 (10):2707-2715. doi:10.1093/jxb/ern131

Komatsuda T, Pourkheirandish M, He C, Azhaguvel P, Kanamori H, Perovic D, Stein N, Graner A, Wicker T, Tagiri A, Lundqvist U, Fujimura T, Matsuoka M, Matsumoto T, Yano M (2007) Six-rowed barley originated from a mutation in a homeodomainleucine zipper I-class homeobox gene. Proceedings of the National Academy of Sciences 104 (4):1424-1429. doi:10.1073/pnas.0608580104

Komatsuda T, Tanno K-i, Salomon Br, Bryngelsson T, Bothmer Rv (1999) Phylogeny in the genus Hordeum based on nucleotide sequences closely linked to the vrs1 locus (row number of spikelets). Genome 42 (5):973-981. doi:10.1139/g99-025

Komatsuda TK, Mano YM (2002) Molecular mapping of the intermedium spike-c (int-c) and non-brittle rachis 1 (btrl) loci in barley (Hordeum vulgare L.). TAG 105 (1):85-90. doi:10.1007/s00122-001-0858-0

Li Y, Schwarz PB, Barr JM, Horsley RD (2008) Factors predicting malt extract within a single barley cultivar. Journal of Cereal Science 48 (2):531-538. doi:10.1016/j.jcs.2007.12.004 
March TJ, Richter D, Colby T, Harzen A, Schmidt J, Pillen K (2012) Identification of proteins associated with malting quality in a subset of wild barley introgression lines. Proteomics 12 (18):2843-2851. doi:10.1002/pmic.201200117

Marquez-Cedillo LA, Hayes PM, Jones BL, Kleinhofs A, Legge WG, Rossnagel BG, Sato K, Ullrich SE, Wesenberg DM (2000) QTL analysis of malting quality in barley based on the doubled-haploid progeny of two elite North American varieties representing different germplasm groups. TAG 101 (1):173-184. doi:10.1007/s001220051466

Marquez-Cedillo LA, Hayes PM, Kleinhofs A, Legge WG, Rossnagel BG, Sato K, Ullrich SE, Wesenberg DM (2001) QTL analysis of agronomic traits in barley based on the doubled haploid progeny of two elite North American varieties representing different germplasm groups. TAG 103 (4):625-637. doi:10.1007/p100002919

Mather DE, Tinker NA, LaBerge DE, Edney M, Jones BL, Rossnagel BG, Legge WG, Briggs KG, Irvine RB, Falk DE, Kasha KJ (1997) Regions of the genome that affect grain and malt quality in a North American two-row barley cross. Crop Science 37 (2):544554

Mayolle JE, Lullien-Pellerin V, Corbineau F, Boivin P, Guillard V (2012) Water diffusion and enzyme activities during malting of barley grains: A relationship assessment. Journal of Food Engineering 109 (3):358-365. doi:10.1016/j.jfoodeng.2011.11.021

Moody DB, Tait S, Walker C, Panozzo JP, Emebiri LC, Hayden M (2009) Genetic dissection of grain plumpness in barley. Paper presented at the The proceedings of the 14th Australian Barley Technical Symposium, Sunshine Coast,

Morris CF, DeMacon VL, Giroux MJ (1999) Wheat grain hardness among chromosome 5D homozygous recombinant substitution lines using different methods of measurement. Cereal Chemistry 76 (2):249-254

Muñoz-Amatriaín M, Moscou MJ, Bhat PR, Svensson JT, Bartoš J, Suchánková P, Šimková H, Endo TR, Fenton RD, Lonardi S, Castillo AM, Chao S, Cistué L, Alfonso, CuestaMarcos, Forrest KL, Hayden MJ, Hayes PM, Horsley RD, Makoto K, Moody D, Sato K, Vallés MP, Wulff BBH, Muehlbauer GJ, Doležel J, Close TJ (2011) An improved consensus linkage map of barley based on flow-sorted chromosomes and single nucleotide polymorphism markers. The Plant Genome 4 (3):238-249. doi:10.3835/plantgenome2011.08.0023

Nair S, Knoblauch M, Ullrich S, Baik B-K (2011) Microstructure of hard and soft kernels of barley. Journal of Cereal Science 54 (3):354-362. doi:10.1016/j.jcs.2011.06.014

Nair S, Ullrich SE, Blake TK, Cooper B, Griffey CA, Hayes PM, Hole DJ, Horsley RD, Obert DE, Smith KP, Muehlbauer GJ, Baik BK (2010) Variation in kernel hardness and associated traits in U.S. barley breeding lines. Cereal Chemistry 87 (5):461-466. doi:10.1094/cchem-12-09-0163

Natsuga M, Kawamura S (2006) Visible and near-infrared reflectance spectroscopy for determining physicochemical properties of rice. Transactions of the ASABE 49 (4):1069-1076 
Nielsen JP (2003) Evaluation of malting barley quality using exploratory data analysis. II. The use of kernel hardness and image analysis as screening methods. Journal of Cereal Science 38 (3):247-255. doi:10.1016/S0733-5210(03)00024-9

Panozzo JF, Eckermann PJ, Mather DE, Moody DB, Black CK, Collins HM, Barr AR, Lim P, Cullis BR (2007) QTL analysis of malting quality traits in two barley populations. AJAR 58 (9):858-866. doi:10.1071/AR06203

Pearson T, Wilson J, Gwirtz J, Maghirang E, Dowell F, McCluskey P, Bean S (2007) Relationship between single wheat kernel particle-size distribution and Perten SKCS 4100 hardness index. Cereal Chemistry 84 (6):567-575

Psota V, Vejrazka K, Famera O, Hrcka M (2007) Relationship between grain hardness and malting quality of barley (Hordeum vulgare L.). J Inst Brew 113 (1):80-86. doi:10.1002/j.2050-0416.2007.tb00260.x

Ramsay L, Comadran J, Druka A, Marshall DF, Thomas WTB, Macaulay M, MacKenzie K, Simpson C, Fuller J, Bonar N, Hayes PM, Lundqvist U, Franckowiak JD, Close TJ, Muehlbauer GJ, Waugh R (2011) INTERMEDIUM-C, a modifier of lateral spikelet fertility in barley, is an ortholog of the maize domestication gene TEOSINTE BRANCHED. Nature Genetics 43 (2):169-172. doi:10.1038/ng.745

Swanston JS (1995) Effects on barley-grain size, texture and modification during malting associated with 3 genes on chromosome-1. Journal of Cereal Science 22 (2):157-161. doi:10.1016/0733-5210(95)90045-4

Sýkorová A, Sarka E, Bubník Z, Schejba M, Dostálek P (2009) Size distribution of barley kernels. Czech Journal of Food Science 27 (4):249-258

Szücs P, Blake VC, Bhat PR, Chao S, Close TJ, Cuesta-Marcos A, Muehlbauer GJ, Ramsay L, Waugh R, Hayes PM (2009) An integrated resource for barley linkage map and malting quality QTL alignment. The Plant Genome 2 (2):134-140. doi:10.3835/plantgenome2008.01.0005

Szücs P, Karsai I, von Zitzewitz J, Mészáros K, Cooper L, Gu Y, Chen T, Hayes P, Skinner J (2006) Positional relationships between photoperiod response QTL and photoreceptor and vernalization genes in barley. TAG 112 (7):1277-1285. doi:10.1007/s00122-0060229-y

Szücs P, Skinner J, Karsai I, Cuesta-Marcos A, Haggard K, Corey A, Chen T, Hayes P (2007) Validation of the $V R N-H 2 / V R N-H 1$ epistatic model in barley reveals that intron length variation in $V R N-H 1$ may account for a continuum of vernalization sensitivity. Molecular Genetics and Genomics 277 (3):249-261. doi:10.1007/s00438-006-0195-8

Takahashi A, Ikeda T, Takayama T, Yanagisawa T (2010) A barley hordoindoline mutation resulted in an increase in grain hardness. TAG 120 (3):519-526. doi:10.1007/s00122$009-1172-5$

Thomas WTB, Powell W, Swanston JS, Ellis RP, Chalmers KJ, Barua UM, Jack P, Lea V, Forster BP, Waugh R, Smith DB (1996) Quantitative trait loci for germination and 
malting quality characters in a spring barley cross. Crop Science 36 (2):265-273. doi:10.2135/cropsci1996.0011183X003600020009x

Turuspekov Y, Beecher B, Darlington Y, Bowman J, Blake TK, Giroux MJ (2008) Hardness locus sequence variation and endosperm texture in spring barley. Crop Science 48 (3):1007-1019. doi:10.2135/cropsci2007.08.0424

Voorrips RE (2002) MapChart: Software for the graphical presentation of linkage maps and QTLs. Journal of Heredity 93 (1):77-78. doi:10.1093/jhered/93.1.77

Walker C, Panozzo J, Ford R, Eckermann P, Moody D, Lehmensiek A, Appels R (2011) Chromosomal loci associated with endosperm hardness in a malting barley cross. TAG 122 (1):151-162. doi:10.1007/s00122-010-1431-5

Walker CK, Panozzo J, Ford R, Moody D (2009) Measuring grain plumpness in barley using image analysis. Paper presented at the The proceedings of the 14th Australian Barley Technical Symposium, Sunshine Coast,

Walker CK, Panozzo JF (2011) Development of a small scale method to determine volume and density of individual barley kernels, and the relationship between grain density and endosperm hardness. Journal of Cereal Science 54 (3):311-316. doi:10.1016/j.jcs.2011.06.008

Walker CK, Panozzo JF (2012) Measuring volume and density of a barley grain using ellipsoid approximation from a 2-D digital image. Journal of Cereal Science 55 (1):6168. doi:10.1016/j.jcs.2011.10.004

Wang L, Li G, Xia X, He Z, Mu P (2008) Molecular characterization of Pina and Pinb allelic variations in Xinjiang landraces and commercial wheat cultivars. Euphytica 164 (3):745-752. doi:10.1007/s10681-008-9706-5

Williams K, Munkvold J, Sorrells M (2012) Comparison of digital image analysis using elliptic Fourier descriptors and major dimensions to phenotype seed shape in hexaploid wheat (Triticum aestivum L.). Euphytica:1-18. doi:10.1007/s10681-0120783-0

Williams PC, Norris K (2001) Near-infrared technology in the agricultural and food industries, 2nd Ed. Am. Assoc. Cereal Chem., St. Paul, MN.

Wu Y, Bhat PR, Close TJ, Lonardi S (2008) Efficient and accurate construction of genetic linkage maps from the minimum spanning tree of a graph. PLoS Genet 4:e1000212

$\mathrm{Xu}$ Y, Crouch JH (2008) Marker-assisted selection in plant breeding: from publications to practice. Crop Science 48 (2):391-407. doi:10.2135/cropsci2007.04.0191 

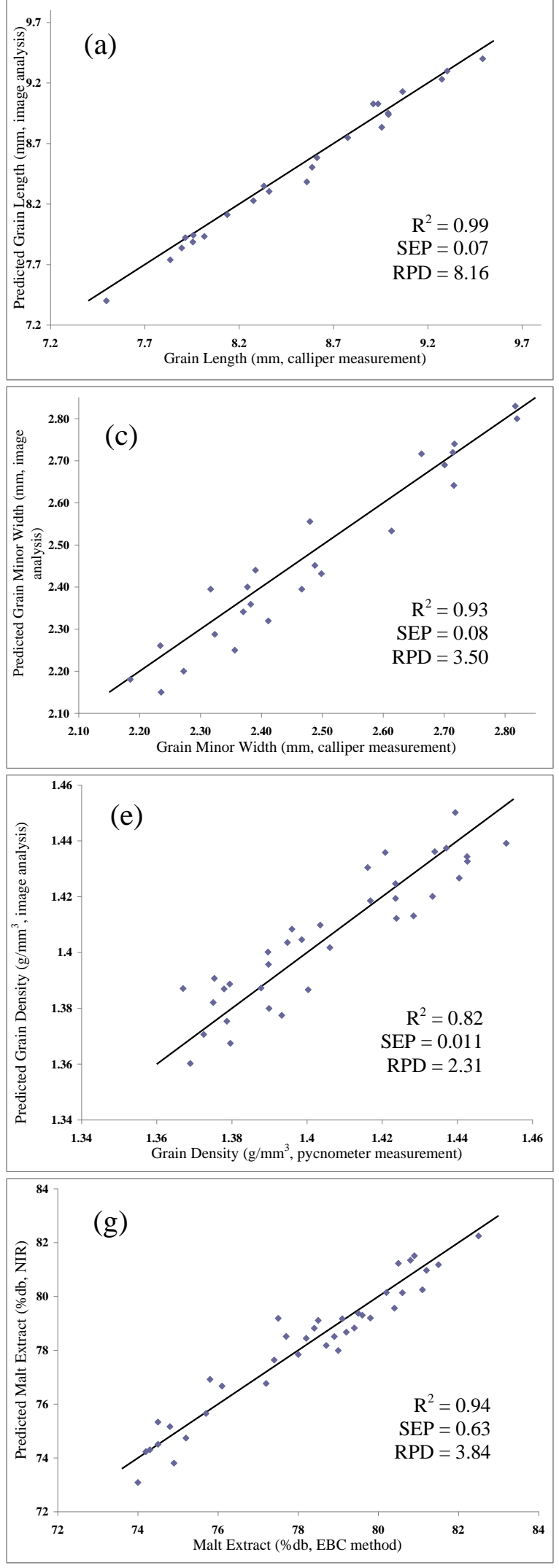
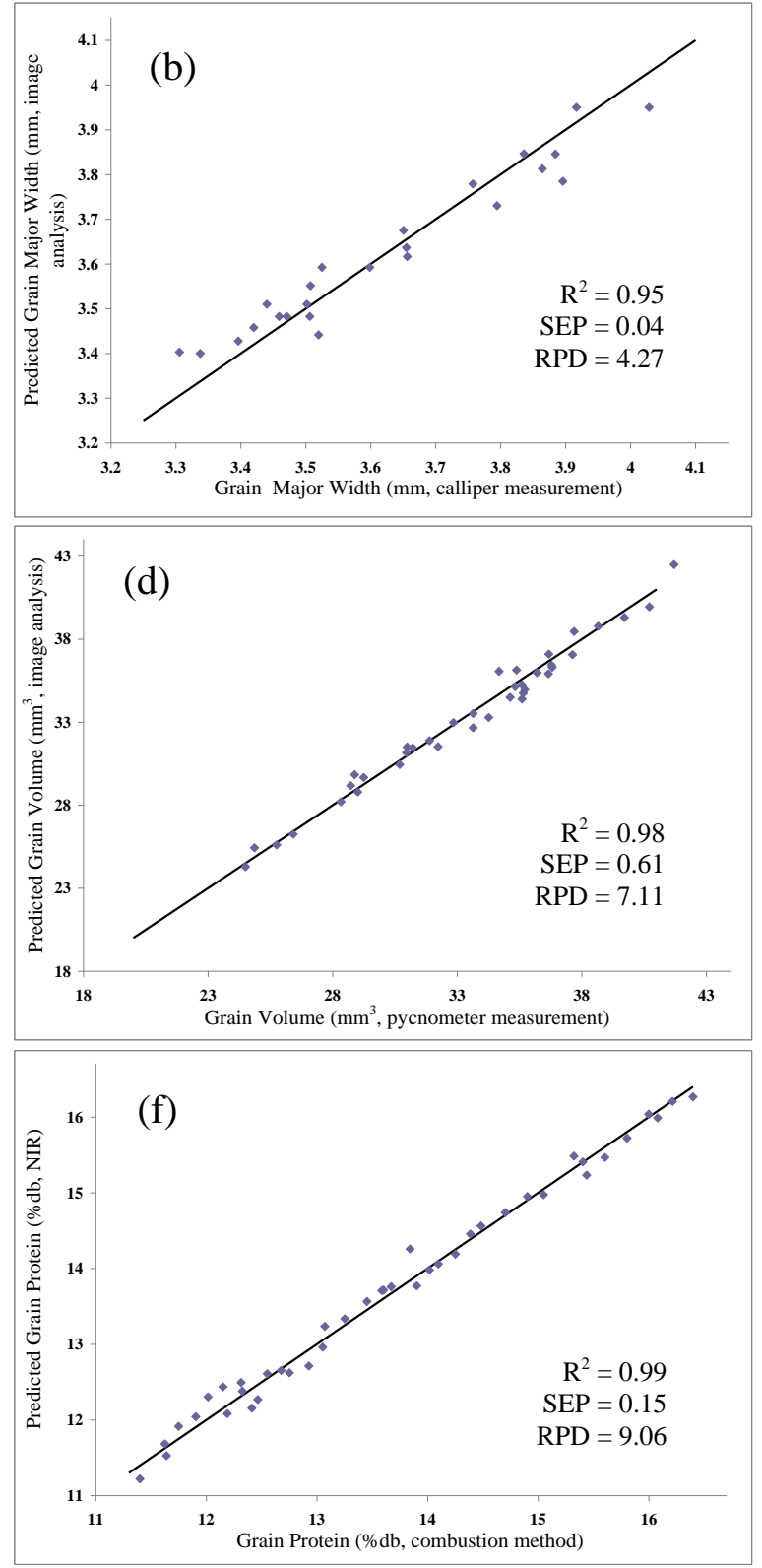

Fig. 1 Scatter plots of the validation data: a measured grain length plotted against the DIA predicted values; b measured grain major-width plotted against the DIA predicted values; c measured grain minor-width plotted against the DIA predicted values; d gas displacement grain volume plotted against the DIA predicted values; e grain densities calculated from gas displacement volume plotted against the DIA predicted values; f reference grain protein content plotted against the NIR predicted values; $g$ reference malt extract content plotted against the NIR predicted values; with a 1:1 line of best fit (solid line). 
$1 \mathrm{H}$
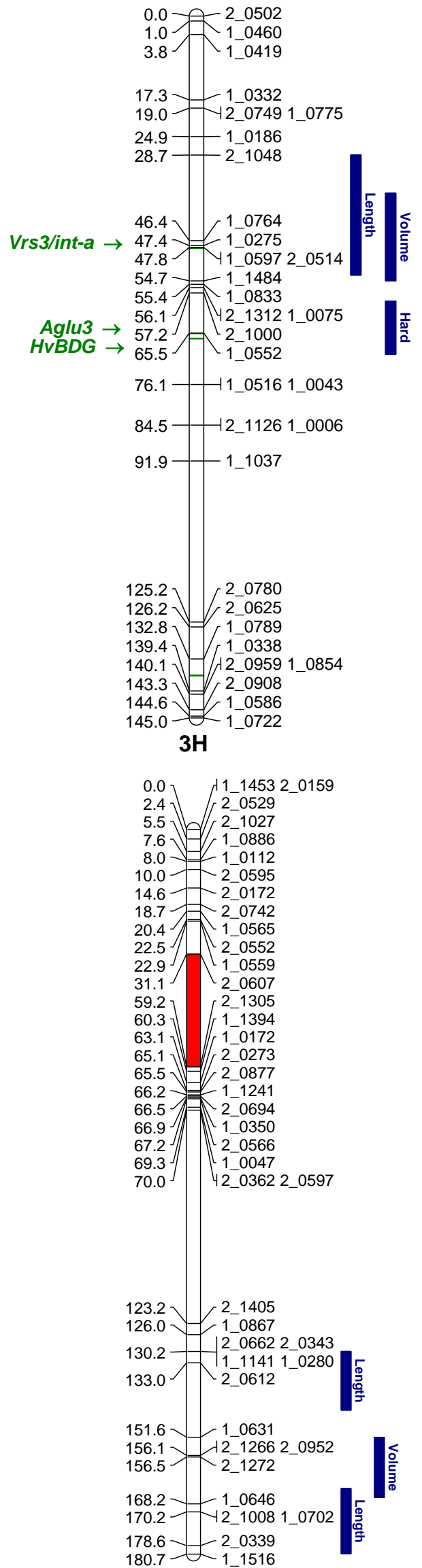

$2 \mathrm{H}$

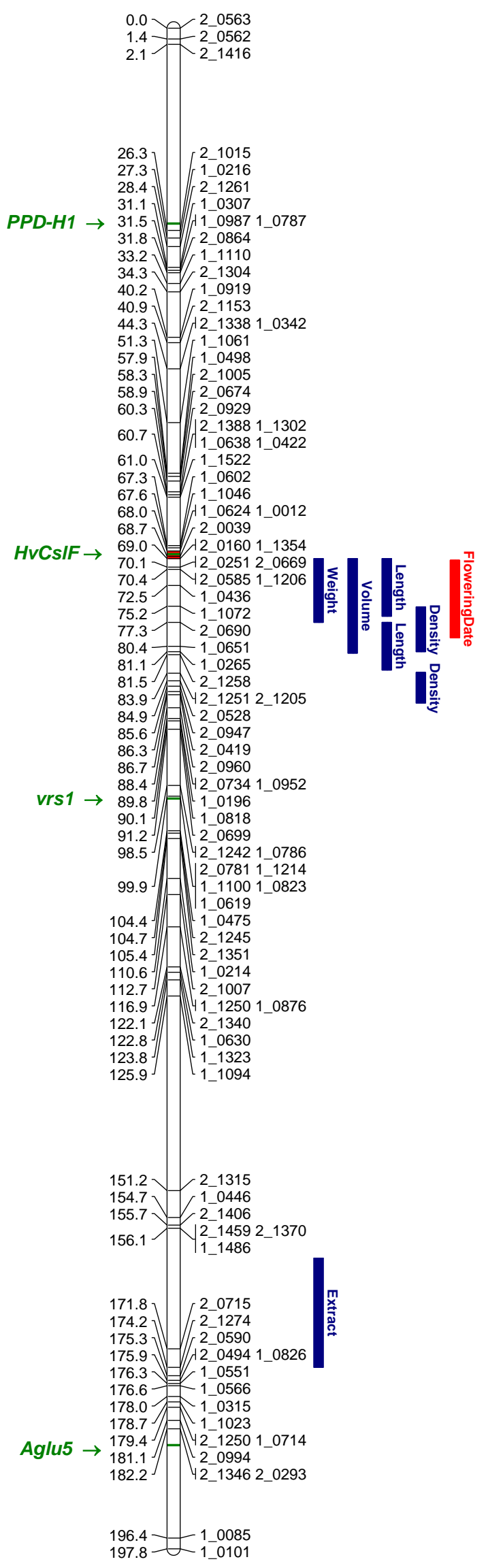


4H

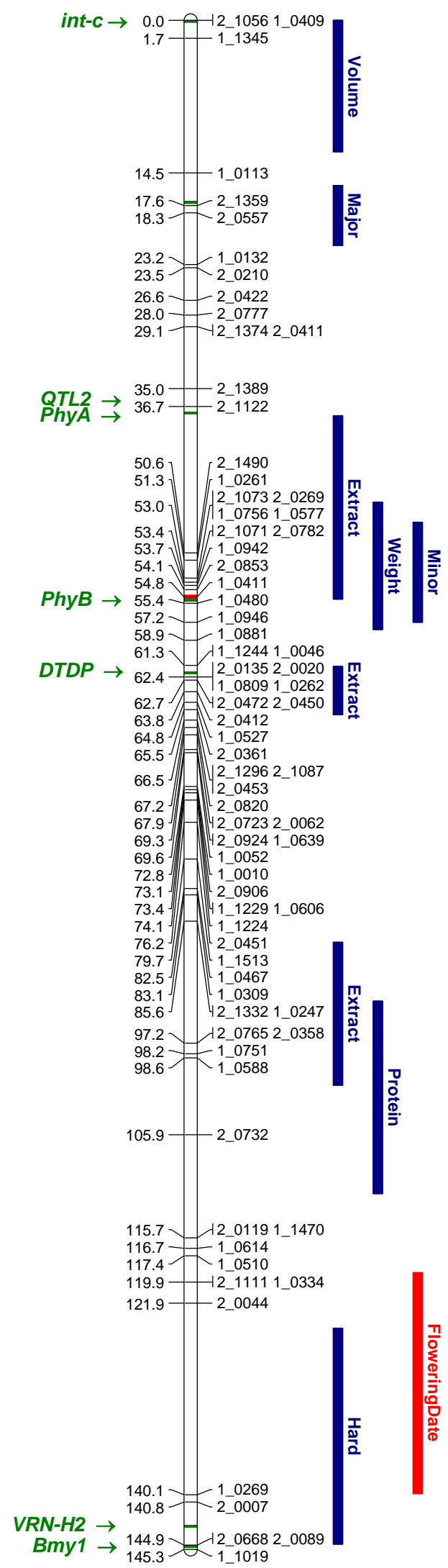

$5 \mathrm{H}$

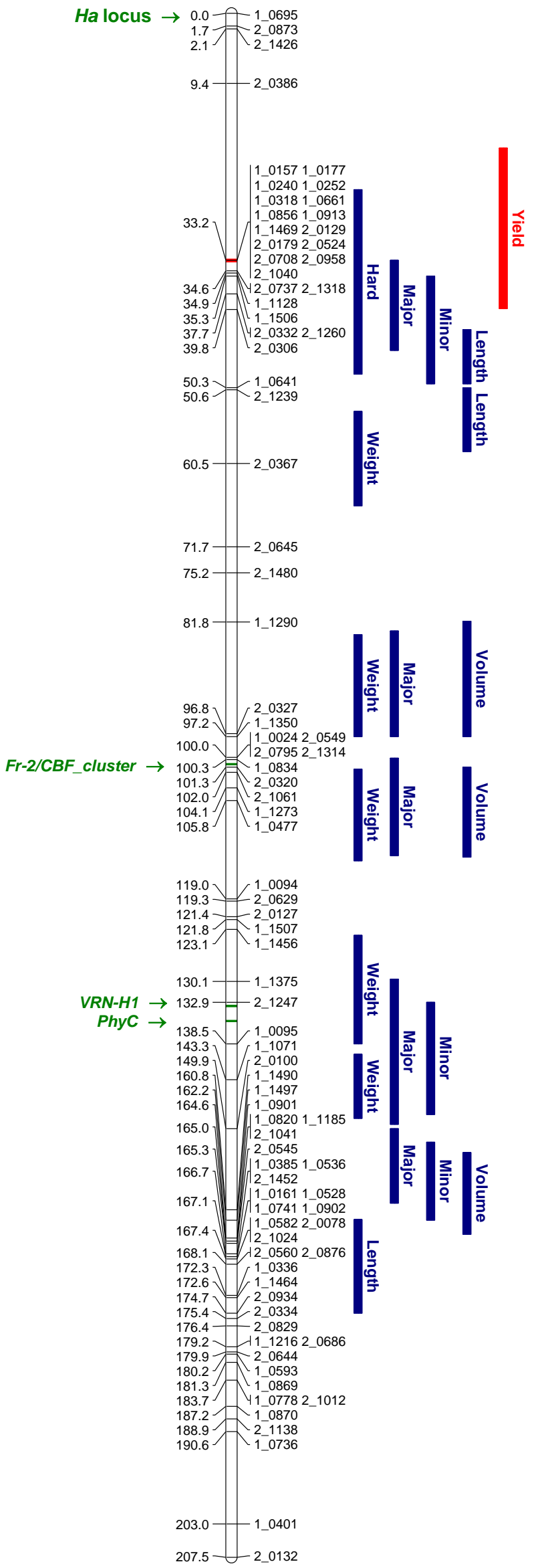


$6 \mathrm{H}$

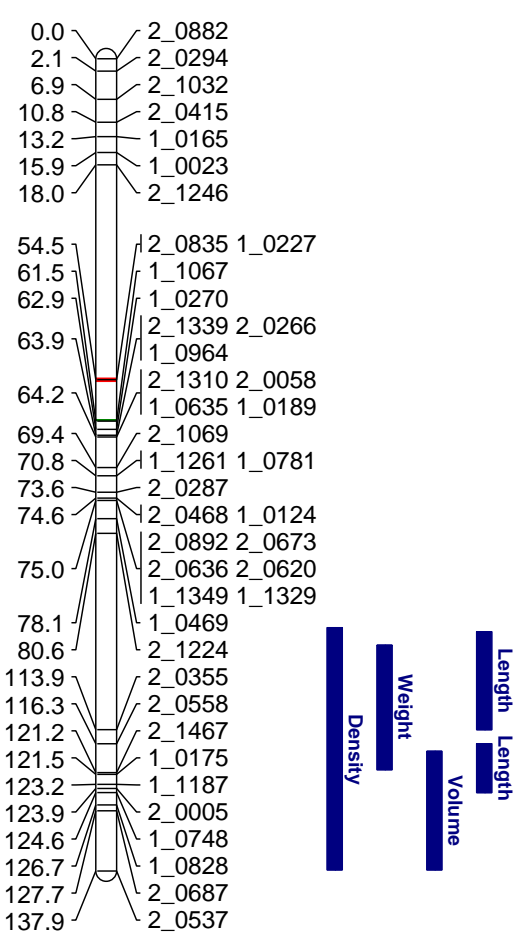

$7 \mathrm{H}$

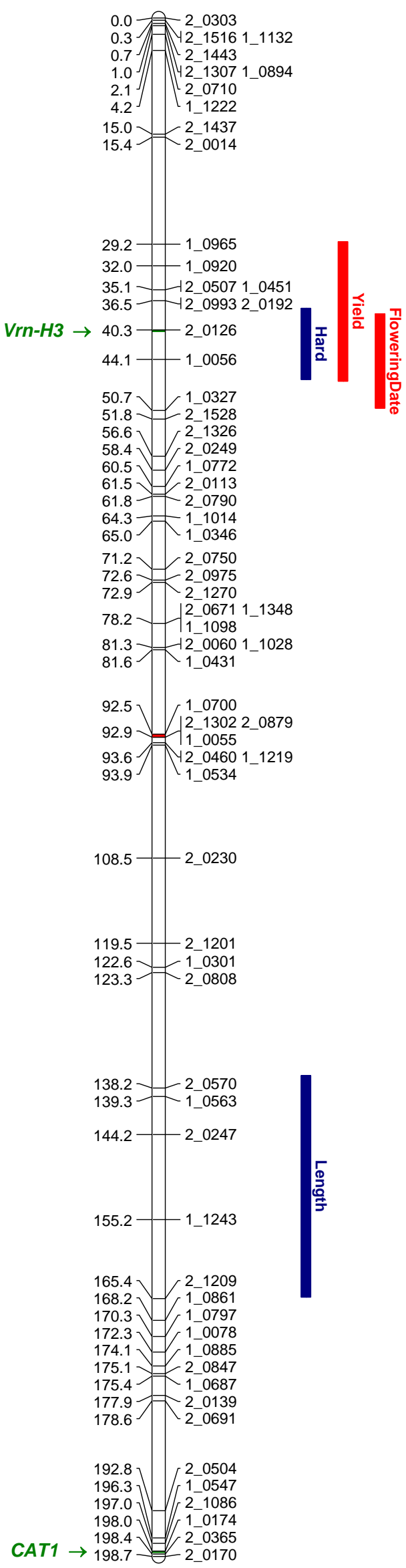


Fig. 2. The genetic map of the 'Vlamingh' $\times$ 'Buloke' $\mathrm{DH}$ mapping population and associated consensus quantitative trait loci (QTLs) observed for endosperm hardness (hard), grain density (density), grain volume (volume), malt extract (extract), grain length (length), minor-width (minor), major-width (major), and grain protein content (protein), across at least two environments (blue). QTLs observed for grain yield and flowering date, across at least two environments (red). Markers are presented to a scale of genetic distance (centiMorgans). Other loci related to malting quality and plant development were aligned based on the historical markers integrated into the barley consensus map (Muñoz-Amatriaín et al. 2011) or the OWB integrated map (Szücs et al. 2009), and are presented on the left indicated by an arrow in bold italics (green).

Table 1. Mean values and standard errors for endosperm hardness, grain density, malt extract, grain protein content, grain weight, grain volume, grain length, major-width, minorwidth, grain yield and flowering date in the 'Vlamingh' $\times$ 'Buloke' DH mapping population.

\begin{tabular}{|c|c|c|c|c|c|c|c|}
\hline & $\begin{array}{c}\text { Endosperm } \\
\text { Hardness } \\
\text { (SK units) }\end{array}$ & $\begin{array}{c}\text { Grain } \\
\text { Density } \\
\left(\mathrm{g} / \mathrm{mm}^{3}\right)\end{array}$ & $\begin{array}{c}\text { Malt } \\
\text { Extract } \\
(\% \mathrm{db})\end{array}$ & $\begin{array}{c}\text { Grain } \\
\text { Protein } \\
(\% \mathrm{db})\end{array}$ & $\begin{array}{c}\text { Grain } \\
\text { Weight } \\
(\mathrm{mg})\end{array}$ & $\begin{array}{c}\text { Grain } \\
\text { Volume } \\
\left(\mathrm{mm}^{3}\right)\end{array}$ & $\begin{array}{c}\text { Grain } \\
\text { Length } \\
(\mathrm{mm})\end{array}$ \\
\hline \multicolumn{8}{|l|}{ Lake Bolac, rainfed } \\
\hline Vlamingh & $47.61^{\mathrm{a}}$ & $1.384^{\mathrm{a}}$ & $78.73^{\mathrm{a}}$ & 14.09 & $46.00^{\mathrm{a}}$ & $33.24^{\mathrm{a}}$ & $7.84^{\mathrm{a}}$ \\
\hline Buloke & $51.77^{\mathrm{a}}$ & $1.391^{\mathrm{a}}$ & $79.81^{\mathrm{a}}$ & 13.68 & $50.99^{\mathrm{a}}$ & $37.42^{\mathrm{a}}$ & $8.94^{\mathrm{a}}$ \\
\hline DHL Maximum & 66.70 & 1.413 & 81.95 & 16.27 & 54.07 & 41.69 & 9.18 \\
\hline DHL Minimum & 35.83 & 1.367 & 76.24 & 12.31 & 39.04 & 28.23 & 7.70 \\
\hline DHL Average & 49.83 & 1.391 & 78.78 & 14.14 & 47.29 & 34.79 & 8.41 \\
\hline Least Significant Difference $(\mathrm{P}<0.01)$ & 2.21 & 0.004 & 0.74 & 0.63 & 2.10 & 0.46 & 0.11 \\
\hline Heritability $\left(\mathrm{h}^{2}\right)$ & 0.78 & 0.72 & 0.15 & 0.12 & 0.87 & 0.93 & 0.88 \\
\hline \multicolumn{8}{|l|}{ Horsham, rainfed } \\
\hline Vlamingh & $57.87^{\mathrm{a}}$ & $1.426^{\mathrm{a}}$ & $79.60^{\mathrm{a}}$ & 13.76 & $37.92^{\mathrm{a}}$ & $27.27^{\mathrm{a}}$ & $7.59^{\mathrm{a}}$ \\
\hline Buloke & $62.58^{\mathrm{a}}$ & $1.431^{\mathrm{a}}$ & $80.80^{\mathrm{a}}$ & 13.45 & $41.66^{\mathrm{a}}$ & $30.85^{\mathrm{a}}$ & $8.57^{\mathrm{a}}$ \\
\hline DHL Maximum & 78.16 & 1.453 & 82.12 & 16.45 & 46.15 & 32.85 & 8.87 \\
\hline DHL Minimum & 45.90 & 1.399 & 76.42 & 11.94 & 34.55 & 24.48 & 7.39 \\
\hline DHL Average & 61.99 & 1.428 & 79.32 & 14.09 & 39.44 & 28.82 & 8.12 \\
\hline Least Significant Difference $(\mathrm{P}<0.01)$ & 1.75 & 0.004 & 0.60 & 0.63 & 1.12 & 0.63 & 0.04 \\
\hline Heritability $\left(h^{2}\right)$ & 0.80 & 0.60 & 0.79 & 0.75 & 0.75 & 0.90 & 0.93 \\
\hline \multicolumn{8}{|l|}{ Horsham, irrigation } \\
\hline Vlamingh & $41.43^{\mathrm{a}}$ & $1.396^{\mathrm{a}}$ & $78.70^{\mathrm{a}}$ & $13.82^{\mathrm{a}}$ & $44.04^{\mathrm{a}}$ & $32.23^{\mathrm{a}}$ & $7.89^{\mathrm{a}}$ \\
\hline Buloke & $55.22^{\mathrm{a}}$ & $1.405^{\mathrm{a}}$ & $80.11^{\mathrm{a}}$ & $12.95^{\mathrm{a}}$ & $47.98^{\mathrm{a}}$ & $36.21^{\mathrm{a}}$ & $9.15^{\mathrm{a}}$ \\
\hline DHL Maximum & 62.22 & 1.431 & 82.98 & 16.35 & 52.30 & 39.04 & 9.43 \\
\hline DHL Minimum & 31.96 & 1.377 & 76.00 & 11.41 & 38.09 & 27.80 & 7.68 \\
\hline DHL Average & 47.32 & 1.405 & 79.04 & 13.62 & 45.44 & 33.84 & 8.53 \\
\hline Least Significant Difference $(\mathrm{P}<0.01)$ & 2.10 & 0.007 & 0.60 & 0.53 & 1.82 & 1.02 & 0.14 \\
\hline Heritability $\left(\mathrm{h}^{2}\right)$ & 0.77 & 0.66 & 0.68 & 0.61 & 0.68 & 0.67 & 0.81 \\
\hline
\end{tabular}

Table 2. Correlations coefficients $(r)$ for endosperm hardness, grain density, malt extract, grain protein content, grain weight, grain volume, grain length, major-width, and minor-width in the 'Vlamingh' $\times$ 'Buloke' DH mapping population grown at three environments. 


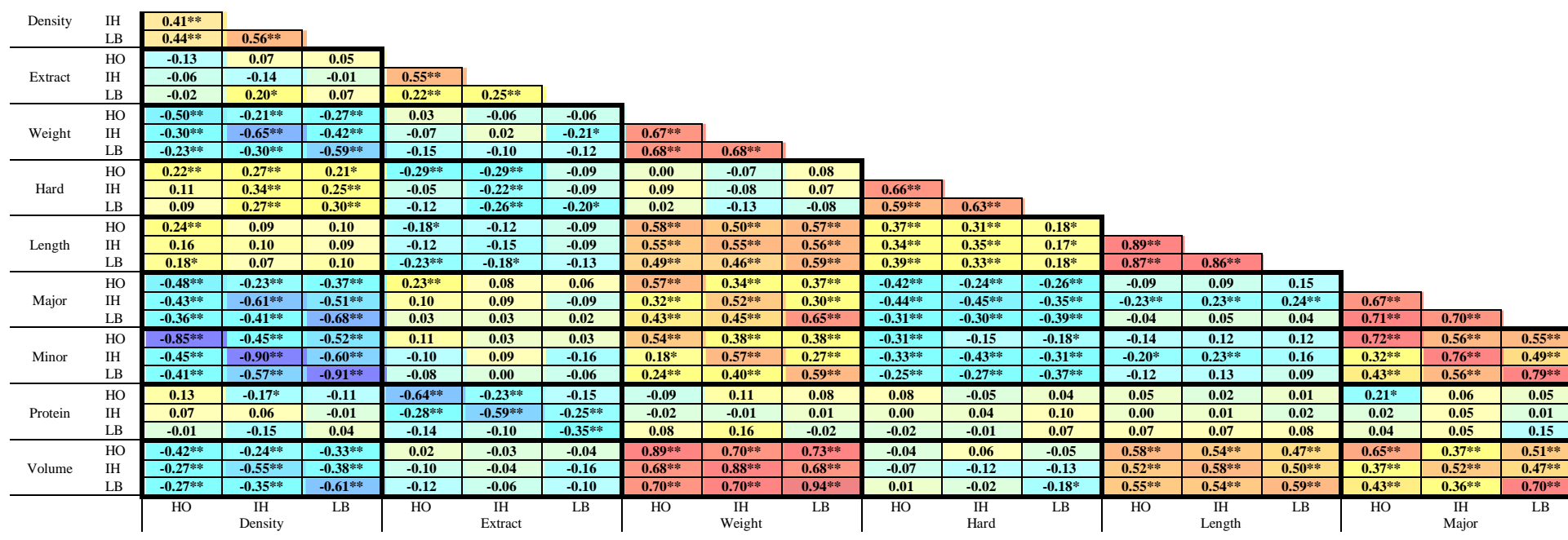

Correlations tested using a two-tailed test at the significance levels $0.001\left(^{* *}\right)$ and $0.01\left(^{*}\right)$, HO: Horsham rainfed, IH: Horsham irrigated, LB: Lake Bolac rainfed, Density: grain density $\left(\mathrm{g} / \mathrm{mm}^{3}\right)$, Extract: malt extract content $(\%$, db), Weight: grain weight (mg), Hard: endosperm hardness (SKCS units), Length: grain length (mm), Major: grain major-width (mm), Minor: grain minor-width $(\mathrm{mm})$, Protein: grain protein content $(\%, d b)$, and Volume: grain volume $\left(\mathrm{mm}^{3}\right)$.

Table 3. Consensus genomic regions of the significant QTLs for endosperm hardness, grain density, grain volume, malt extract, grain protein, grain weight, grain length, major-width, and minor-width analysed in the 'Vlamingh' $\times$ 'Buloke' DH mapping population across at least two environments.

\begin{tabular}{cccccccc}
\hline Chr & Env & $\begin{array}{c}\text { Position } \\
(\mathbf{c M})\end{array}$ & LOD & $\begin{array}{c}\text { \% Var. } \\
\text { Exp, } \mathbf{R}^{2}\end{array}$ & \multicolumn{1}{c}{ Additive effect } & $\begin{array}{c}\text { Higher } \\
\text { Parent }\end{array}$ & Marker Interval \\
\hline \multicolumn{7}{c}{ Endosperm Hardness (SK units) } \\
1 & 3 & $61.2-65.2$ & $8.8-19.9$ & $10.8-21.7$ & $-(2.72-2.08)$ & Buloke & 2_1000-1_0552 \\
4 & 2 & 133.9 & $2.7-4.1$ & $3.2-4.8$ & $1.00-1.33$ & Vlamingh & 2_0044-2_0007 \\
5 & 3 & $33.2-43.8$ & $4.3-9.4$ & $4.3-12.5$ & $1.24-2.06$ & Vlamingh & 2_0386-2_0306
\end{tabular}




\begin{tabular}{|c|c|c|c|c|c|c|c|}
\hline 7 & 2 & $40.3-42.3$ & $5.1-7.3$ & $5.3-6.8$ & $1.39-1.46$ & Vlamingh & 2_0993-1_0056 \\
\hline \multicolumn{8}{|c|}{ Grain Density $\left(\mathrm{g} / \mathrm{mm}^{3}\right)$} \\
\hline 2 & 2 & $77.3-79.3$ & $3.1-7.3$ & $4.0-8.8$ & $-(0.014-0.008)$ & Buloke & 1_1072-1_0651 \\
\hline 2 & 2 & $85.7-86.7$ & $4.6-5.6$ & $5.7-6.8$ & $-(0.012-0.010)$ & Buloke & 2_1258-2_0960 \\
\hline 6 & 2 & $115.9-123.9$ & $3.1-6.3$ & $3.9-8.2$ & $-(0.012-0.007)$ & Buloke & 2_1224-2_0687 \\
\hline \multicolumn{8}{|c|}{ Malt Extract (\% w/w, dry basis) } \\
\hline 2 & 2 & $168.1-170.1$ & $5.1-5.2$ & $4.7-5.3$ & $-(0.25-0.24)$ & Buloke & 2_1459-2_0715 \\
\hline 4 & 2 & $44.7-54.1$ & $4.2-13.1$ & $7.9-13$ & $0.33-0.42$ & Vlamingh & 2_1122-1_0411 \\
\hline 4 & 2 & $62.4-63.8$ & 4.4-10.1 & $3.5-10.3$ & $0.23-0.39$ & Vlamingh & 1_1244-2_0361 \\
\hline 4 & 2 & $93.6-95.6$ & $2.7-3.7$ & $2.6-3.5$ & $0.18-0.23$ & Vlamingh & 2_1332-1_0588 \\
\hline \multicolumn{8}{|c|}{ Protein $(\%$ w/w, dry basis $)$} \\
\hline 4 & 2 & $98.2-105.9$ & $3.3-6.5$ & $4.0-6.8$ & $-(0.21-0.16)$ & Buloke & 2_1332-2_0732 \\
\hline \multicolumn{8}{|c|}{ Grain Weight (mg) } \\
\hline 2 & 3 & $70.1-72.5$ & $6.3-12.6$ & $6.6-12.5$ & $0.62-0.80$ & Vlamingh & 2_0039-1_1072 \\
\hline 4 & 3 & $51.3-55.5$ & $3.4-8.7$ & $3.1-9.7$ & $-(0.87-0.37)$ & Buloke & 2_1122-1_0946 \\
\hline 5 & 3 & $58.6-60.5$ & $5.3-9.3$ & $5.8-9.1$ & $0.57-0.76$ & Vlamingh & 2_1239-2_0367 \\
\hline 5 & 2 & 91.8 & 4.6-4.7 & $5.3-6.7$ & $-(0.78-0.53)$ & Buloke & 1_1290-1_1350 \\
\hline 5 & 3 & 105.8 & 3.3-6.7 & 3.3-7.3 & $-(0.85-0.46)$ & Buloke & 2_0320-1_0477 \\
\hline 5 & 3 & $127.2-132.9$ & 3.8-5.9 & $3.6-6.4$ & $0.44-0.97$ & Vlamingh & 1_1456-1_0095 \\
\hline 5 & 2 & $140.5-145.3$ & $5.5-7.1$ & $6.7-8.3$ & $0.72-0.76$ & Vlamingh & 1_0095-1_1071 \\
\hline 6 & 2 & 113.9 & 2.6-5.9 & 2.6-5.6 & $0.39-0.49$ & Vlamingh & 2_1224-2_0558 \\
\hline \multicolumn{8}{|c|}{ Grain Volume $\left(\mathrm{mm}^{3}\right)$} \\
\hline 1 & 2 & 47.4 & $3.0-3.3$ & $2.4-2.7$ & $-(0.31-0.25)$ & Buloke & 2_1048-2_0514 \\
\hline 2 & 3 & $70.1-79.3$ & $16.6-19.5$ & $15.3-19.3$ & $0.71-0.90$ & Vlamingh & 2_0039-1_0265 \\
\hline 3 & 2 & $156.5-158.5$ & $3.7-4.2$ & 3.3-3.4 & $-(0.37-0.37)$ & Buloke & 2_0612-2_1272 \\
\hline 4 & 3 & $0.0-1.7$ & $2.6-5.5$ & $2.1-4.6$ & $0.29-0.32$ & Vlamingh & 2_1056-1_1345 \\
\hline 5 & 2 & $87.8-89.8$ & $2.7-6.6$ & $2.8-7.3$ & $-(0.48-0.38)$ & Buloke & 2_1480-1_1350 \\
\hline 5 & 3 & $102.0-105.8$ & $4.1-8.3$ & $3.4-7.2$ & $-(0.50-0.44)$ & Buloke & 1_0834-1_0477 \\
\hline 5 & 2 & $159.9-160.8$ & $3.5-3.6$ & 2.9-2.9 & $0.36-0.39$ & Vlamingh & 2_0100-1_1497 \\
\hline 6 & 3 & $121.2-135.7$ & 4.8-11.6 & $4.4-10.2$ & $0.44-0.64$ & Vlamingh & 2_0558-2_0687 \\
\hline \multicolumn{8}{|c|}{ Grain Length (mm) } \\
\hline 1 & 3 & $34.7-47.4$ & $5.7-7.3$ & $3.4-5.4$ & $-(0.07-0.07)$ & Buloke & 1_0186-2_0514 \\
\hline 2 & 3 & $70.1-72.5$ & $24.6-33.2$ & $19.2-24.7$ & $0.15-0.18$ & Vlamingh & 2_0039-1_1072 \\
\hline 2 & 3 & $79.3-80.5$ & $21.3-29.5$ & $17.1-23.3$ & $0.14-0.18$ & Vlamingh & 1_1072-2_1258 \\
\hline 3 & 2 & $133.0-137.0$ & $2.7-6.3$ & $1.6-4.8$ & $-(0.08-0.04)$ & Buloke & 2_0662-2_0612 \\
\hline 3 & 3 & $172.3-178.6$ & $3.9-4.6$ & $2.5-2.7$ & $-(0.06-0.05)$ & Buloke & 2_1272-2_0339 \\
\hline 5 & 2 & $45.8-47.8$ & $26.5-28.1$ & $22.4-22.6$ & $0.14-0.17$ & Vlamingh & 2_0306-2_0306 \\
\hline 5 & 2 & 54.6 & $10.1-17.3$ & $7.2-13.8$ & $0.10-0.13$ & Vlamingh & 1_0641-2_1239 \\
\hline 5 & 2 & $172.3-172.6$ & $2.6-3.0$ & $1.5-1.9$ & $-(0.05-0.04)$ & Buloke & 1_1490-2_0934 \\
\hline 6 & 2 & $104.6-106.6$ & $8.9-11.9$ & $9.3-9.9$ & $0.10-0.11$ & Vlamingh & 2_1224-2_0355 \\
\hline 6 & 3 & $120.3-123.9$ & $6.6-10.5$ & $3.9-7.1$ & $0.08-0.10$ & Vlamingh & 2_0558-2_0005 \\
\hline 7 & 3 & $141.3-161.2$ & $3.3-6.6$ & $2.0-4.4$ & $0.05-0.07$ & Vlamingh & 2_0808-1_1243 \\
\hline \multicolumn{8}{|c|}{ Grain Major-width (mm) } \\
\hline 4 & 2 & 18.3 & $5.7-7.9$ & $5.4-7.9$ & $0.02-0.02$ & Vlamingh & 1_0113-2_0557 \\
\hline 5 & 3 & $34.6-39.8$ & $5.5-6.6$ & $5.4-6.3$ & $-(0.02-0.02)$ & Buloke & 1_0157-2_0306 \\
\hline 5 & 2 & 91.8 & $3.8-9.0$ & $4.5-11.8$ & $-(0.03-0.02)$ & Buloke & 1_1290-1_1350 \\
\hline 5 & 3 & $104-109.8$ & $5.8-14.2$ & $5.5-18.2$ & $-(0.03-0.02)$ & Buloke & 1_0024-1_0477 \\
\hline 5 & 3 & $132.9-147.3$ & $6.8-13.7$ & $6.8-14.6$ & $0.02-0.03$ & Vlamingh & 1_1456-1_1071 \\
\hline 5 & 2 & 153.9-155.9 & 7.4-13.9 & $9.9-15.5$ & $0.02-0.03$ & Vlamingh & 1_1071-2_0100 \\
\hline
\end{tabular}

Table 4. Published genes and QTL data in barley associated with plant development and malting quality, and their reported functionality. 


\begin{tabular}{|c|c|c|c|}
\hline Chromosome & Gene/Loci & Functionality & References \\
\hline $1 \mathrm{H}$ & Vrs3 & Morphology modifying gene in 2 row/6 row segregating crosses & (Chutimanitsakun et al. 20 \\
\hline $1 \mathrm{H}$ & int- $a$ & Intermedium spike-a, alter the size of lateral spikelets & (Komatsuda and Mano 200 \\
\hline $1 \mathrm{H}$ & Aglu3 & $\alpha$-glucosidase & (Szücs et al. 2009) \\
\hline $1 \mathrm{H}$ & $H v B D G$ & $(1-3,1-4)-\beta$-D-glucanase & (March et al. 2012; Walker \\
\hline $2 \mathrm{H}$ & $P P D-H 1$ & Photoperiod response & (Karsai et al. 2008) \\
\hline $2 \mathrm{H}$ & $H v C s l F$ & Barley Cellulose synthase-like genes; HvCslF3, HvCslF4, HvCsIF8, and HvCsiF10 & (Burton et al. 2006) \\
\hline $2 \mathrm{H}$ & Vrs1 & $\begin{array}{l}\text { The presence of a recessive allele at the Vrs } 1 \text { locus is sufficient to cause the wild type } \\
\text { two rowed barley to become six-rowed barley }\end{array}$ & (Cuesta-Marcos et al. 2010 \\
\hline $2 \mathrm{H}$ & Aglu5 & $\alpha$-glucosidase & (Szücs et al. 2009) \\
\hline $4 \mathrm{H}$ & int-c & Intermedium spike-c, alter the size of lateral spikelets & (Ramsay et al. 2011) \\
\hline $4 \mathrm{H}$ & $Q T L 2$ & $\begin{array}{l}\text { Moderate effects on several malting quality traits; malt extract, diastatic enzyme } \\
\text { activity, malt } \beta \text {-glucan content, and seed dormancy }\end{array}$ & (Gao et al. 2004) \\
\hline $4 \mathrm{H}$ & PhyA & Phytochromes, involved in regulation of flowering time & (Szücs et al. 2006) \\
\hline $4 \mathrm{H}$ & PhyB & Phytochromes, involved in regulation of flowering time & (Szücs et al. 2006) \\
\hline $4 \mathrm{H}$ & $D T D P$ & d-TDP-glucose dehydratase & (Szücs et al. 2009) \\
\hline $4 \mathrm{H}$ & $V R N-H 2$ & Vernilisation response (formerly $S g h l$ ) & (Szücs et al. 2007) \\
\hline $4 \mathrm{H}$ & Bmyl & $\beta$-amylase & (Szücs et al. 2009) \\
\hline $5 \mathrm{H}$ & $H a$ locus & Reported to modify grain hardness (hordoindolines) & (Beecher et al. 2002; Caldv \\
\hline $5 \mathrm{H}$ & Fr-2/CBR_cluster & Frost Resistance and Dehydration Responsive Elements (DRE)-binding factors & (Galiba et al. 2009) \\
\hline $5 \mathrm{H}$ & $V R N-H 1$ & Vernilisation response, determinant in flowering time (formerly $S g h 2$ ) & (Karsai et al. 2008; Szücs e \\
\hline $5 \mathrm{H}$ & PhyC & Phytochromes, involved in regulation of flowering time & (Szücs et al. 2006) \\
\hline $7 \mathrm{H}$ & $V R N-H 3$ & Vernilisation response, determinant in flowering time & (Karsai et al. 2008) \\
\hline $7 \mathrm{H}$ & CAT1 & Catalase 1 & (Szücs et al. 2009) \\
\hline
\end{tabular}




\section{University Library}

\section{- M M I N E R VA \\ A gateway to Melbourne's research publications}

Minerva Access is the Institutional Repository of The University of Melbourne

Author/s:

Walker, CK;Ford, R;Munoz-Amatriain, M;Panozzo, JF

Title:

The detection of QTLs in barley associated with endosperm hardness, grain density, grain size and malting quality using rapid phenotyping tools

Date:

2013-10-01

\section{Citation:}

Walker, C. K., Ford, R., Munoz-Amatriain, M. \& Panozzo, J. F. (2013). The detection of QTLs in barley associated with endosperm hardness, grain density, grain size and malting quality using rapid phenotyping tools. THEORETICAL AND APPLIED GENETICS, 126 (10), pp.2533-2551. https://doi.org/10.1007/s00122-013-2153-2.

Persistent Link:

http://hdl.handle.net/11343/282645 